\title{
A facile pseudo three component reaction for the synthesis of benzo [4,5]imidazo[I,2-a]pyridine derivatives
}

\section{Abstract}

Background: Benzo[4,5]imidazo[1,2-a]pyridine derivatives were accessed through an efficient pseudo three component reaction between dialdehydes such as o-phthalaldehyde, glutaraldehyde, 2,3-thiophenedicarboxaldehyde and the active methylene 2-(1H-benzo[d]imidazol-2-yl)acetonitrile. The products were obtained in a one-pot manner with easy purification and further characterized by NMR, FT-IR and HRMS spectral data (Figure 1)..

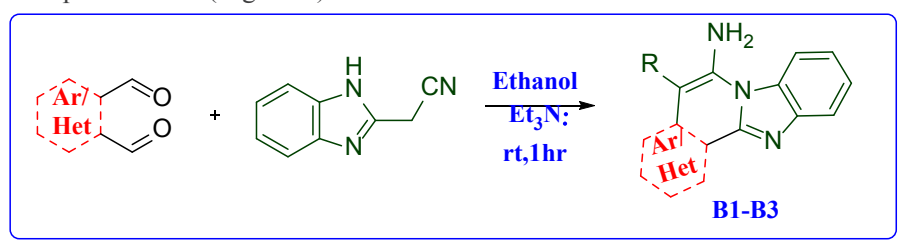

Figure I Benzo [4,5]imidazo[I,2-a]pyridine.

Keywords: MCR, pseudo 3CR, isoquinoline, benzimidazole, one-pot synthesis
Volume 2 Issue 4 - 2018

Gnanasambandam Vasuki, Natarajan Nithya

Department of Chemistry, University of Pondicherry, India

Correspondence: Vasuki Gnanasambandam, Department of Chemistry, University of Pondicherry- R.V. Nagar, Kalapet, Puducherry-6050I4, India, Tel +91948666 3962, +91948666 4962,Email vasukig@gmail.com, vasuki.che@pondiuni.edu.inC

Received: July 31, 2018 | Published: August 15, 2018

\section{Introduction}

The benzimidazole moiety is amongst the diversely active scaffolds as antifungal, antibacterial, antiviral, anticancer and antimalarial agents. ${ }^{1-4}$ Therefore, developing new approaches towards the synthesis of benzimdazole fused heterocycles have always been on need. ${ }^{5}$ Also, indeno and isoquinolino fused heterocycles have gained greater attention because of their medicinal and synthetic importance over years and the broad range of biological activity. ${ }^{6-8}$ Therefore, benzimidazole fused indene, pyridine or isoquinoline are of great interest in general and many synthetic procedures are available till date. ${ }^{1}$ Moved by these results we desired to achieve a facile general synthetic protocol to obtain these diverse molecules. Multicomponent reaction has always proved to be a versatile tool towards the synthesis of structurally diverse and complex heterocycles in simple one pot manner. ${ }^{9}$ Our research group is actively engaged in developing multi-component reaction protocols for the synthesis of skeletally diverse, functionalized and biologically relevant small heterocyclic hybrids. ${ }^{10-12}$ We report a simple and rapid procedure for the preparation of benzo[4,5]imidazo[1,2-a]pyridines (Figure 2) with 2-(1H-benzo[d]imidazol-2-yl)acetonitrile.

\section{Results and discussions}

We planned to perform a three component reaction with a 1,4-dielectrophilic substrate (I) and two carbon nucleophilic building blocks (II \& III) to achieve the scaffold 1a (Figure 2).

Initially, a 3CR was carried out by adding sequentially

i. o-phthalaldehyde,

ii. Malononitrile

iii. 2-(1H-benzo[d]imidazol-2-yl)acetonitrile
In the presence of piperidine as the base in ethanol at room temperature (Figure 2). The resin like product was obtained which could not be purified and characterized. Then, the order of adding the reactants were changed to

a. o-phthalaldehyde,

b. 2-(1H-benzo[d]imidazol-2-yl) acetonitrile

c. Malononitrile (Figure 3)

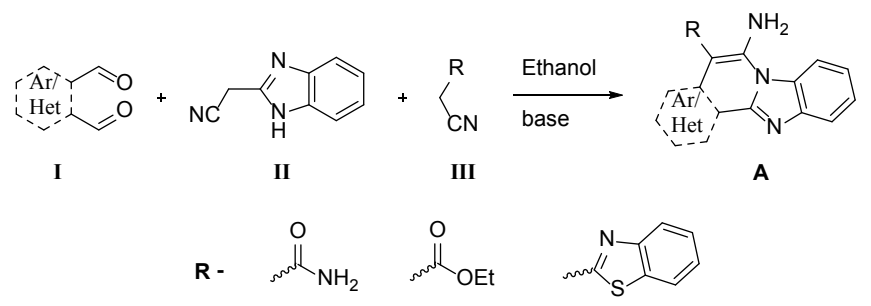

Figure 2 Synthesis of Benzo[4,5]imidazo[1,2-a]pyridine derivative.

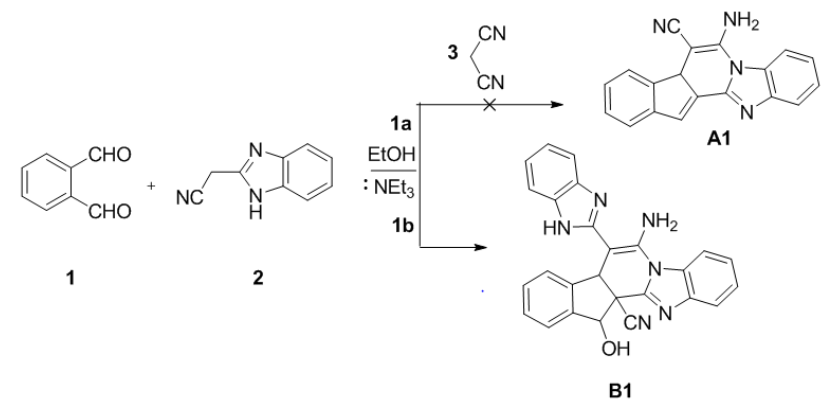

Figure 3 Synthesis of benzo[4,5]imidazo[I,2-a]indeno[2, I-c]pyridine B I derivative. 
A white precipitate formed in twenty minutes which was isolated by filtration, further purified and characterized by NMR to be scaffold B1 (Figure 3) as against the anticipated product A1. Then, the reaction was performed with other solvents and bases to check the feasibility, but no significant improvement in the yield was observed (Table 1). The reaction condition was optimized for ethanol as solvent and triethylamine as base (Table 1 - Entry 3).

Table I Optimization of reaction conditions for synthesis of B I

\begin{tabular}{llllll}
\hline Entry & Catalyst & Time & Solvent & Temp & $\begin{array}{l}\text { Product } \\
\text { yield (B I) }\end{array}$ \\
\hline $\mathrm{I}$ & Piperidine & $\mathrm{I} \mathrm{h}$ & $\mathrm{EtOH}$ & $\mathrm{rt}$ & 75 \\
2 & $\mathrm{Et}_{3} \mathrm{~N}$ & $\mathrm{I} \mathrm{h}$ & $\mathrm{CH}_{3} \mathrm{CN}$ & $\mathrm{rt}$ & 80 \\
3 & $\mathrm{Et}_{3} \mathrm{~N}$ & $\mathrm{I} \mathrm{h}$ & $\mathrm{EtOH}$ & $\mathrm{rt}$ & 89 \\
4 & $\mathrm{Et}_{3} \mathrm{~N}$ & $2 \mathrm{~h}$ & $\mathrm{MeOH}$ & $\mathrm{rt}$ & 75 \\
5 & $\mathrm{~K}_{2} \mathrm{CO}_{3}$ & $24 \mathrm{~h}$ & $\mathrm{CH}_{3} \mathrm{CN}$ & $\mathrm{rt}$ & $\mathrm{Nil}$ \\
6 & $\mathrm{DBU}$ & $2 \mathrm{~h}$ & $\mathrm{CH}_{3} \mathrm{CN}$ & $\mathrm{rt}$ & 55 \\
7 & $\mathrm{P}-\mathrm{TsOH}$ & $24 \mathrm{~h}$ & $\mathrm{H}_{2} \mathrm{O}$ & $\mathrm{rt}$ & $\mathrm{Nil}$ \\
\hline
\end{tabular}

The lack of formation of isolable product in reaction Figure 4 may be due to high reactivity of 2 , with possible formation of more than one unstable product (Figure 4). However when the sequence of addition of nucleophilic reagent is reversed the reaction might follow the path $1 \mathrm{~b}$ shown in Figure 3.<smiles>N#CC(C#N)C1c2ccccc2C(O)C1(C#N)C#N</smiles>

a1<smiles>N#CC1(C#N)Cc2ccccc2C1O</smiles>

a2<smiles>C/C=C\C=C(C#N)C#N</smiles>

B1 accessing skeletally diverse benzo [4,5]imidazo[1,2-a]pyridine derivatives deverivatives with inherent provision for scaffold hopping.

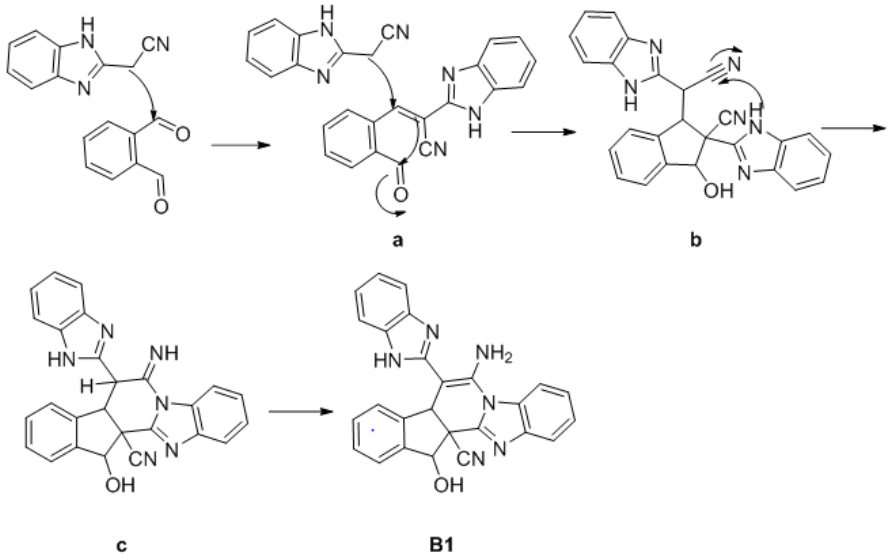

Figure 5 Plausible mechanism for the formation of BI.
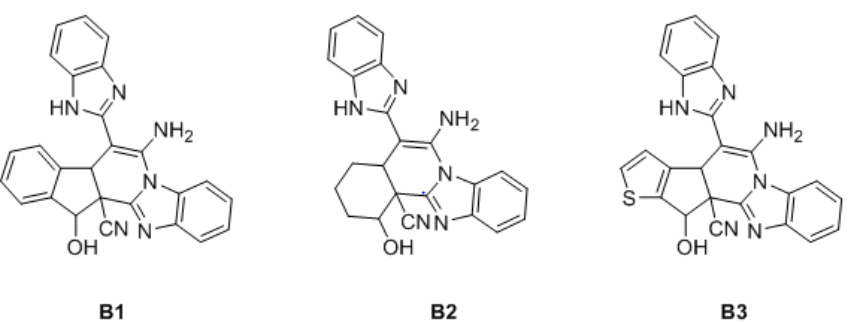

Figure 6 Compounds synthesized from Ib.

\section{Experimental section}

All reactions were performed under normal conditions at room temperature. All chemicals were purchased from Sigma Aldrich, Avra synthesis and were used as received. Deuterated solvents were purchased from Sigma Aldrich. IR spectra were recorded on a Perkin Elmer-FTIR spectrometer using solid samples as $\mathrm{KBr}$ plates. For compounds ${ }^{1} \mathrm{H}$ NMR $\left(400 \mathrm{MHz}, \mathrm{DMSO}-\mathrm{d}_{6}\right)$ and ${ }^{13} \mathrm{C}$ NMR $(100 \mathrm{MHz}$, DMSO- $\mathrm{d}_{6}$ ) spectra were recorded in DMSO- $\mathrm{d}_{6}$ on a Bruker $400 \mathrm{MHz}$ spectrometer using tetramethylsilane $(\mathrm{TMS}, \delta=0$ ) as an internal standard at room temperature. Mass spectra were recorded on Agilent 1200 LC/MS-6110 mass spectrometer (Supporting Information).

\section{6-amino-7-( I H-benzo[d] imidazol-2-yl)- I 2-hydroxy- 7a, I 2-dihydro- 12 aH-benzo $[4,5]$ imidazo $[1,2-a]$ indeno[2, I-c]pyridine- I 2a-carbonitrile (B I)}

Into a round-bottomed flask was added $135 \mathrm{mg}(1 \mathrm{mmol})$ of 1 , $345.8(2.2 \mathrm{mmol})$ of 2 , and trimethylamine $(1 \mathrm{mmol})$ in ethanol. This was stirred at room temperature for an hour. The resulting white precipitate was filtered and washed with methanol to yield $385 \mathrm{mg}$ (nearly $90 \%$ ) of product. ${ }^{1} \mathrm{H}$ NMR $\left(400 \mathrm{MHz}, \mathrm{DMSO}-\mathrm{d}_{6}\right) \delta 13.08(\mathrm{~b}$, $\mathrm{OH}), 8.37\left(\mathrm{~s}, \mathrm{NH}_{2}\right), 8.03(\mathrm{~s}, 1 \mathrm{H}), 7.71(\mathrm{~d}, 1 \mathrm{H}), 7.54(\mathrm{~b}, 2 \mathrm{H}), 7.4-7.3$ $(\mathrm{t}, \mathrm{dd}, 4 \mathrm{H}), 7.1(\mathrm{~s}, 4 \mathrm{H}), 6.8(\mathrm{~d}, 1 \mathrm{H}), 6.04(\mathrm{~s}, 1 \mathrm{H}), 5.65(\mathrm{~s}, 1 \mathrm{H}) \mathrm{ppm}$; $\delta{ }^{13} \mathrm{C}$ NMR (100MHz, DMSO-d $) \delta 153.62,145.24,143.02,142.88$, $142.23,141.19,141.14,133.65,131.24,129.72,128.35,125.48$, $124.69,123.96,123.47,121.63,121.45,120.10,117.67,116.99$ $114.30,110.57,79.76,78.77,56.06,48.63,48.38,45.35,18.58 \mathrm{ppm}$. 
IR $\left(\mathrm{KBr}, v, \mathrm{~cm}^{-1}\right) 3439,3248,2253,1648,1522$. HRMS (ESI) Calcd for $\mathrm{C}_{26} \mathrm{H}_{18} \mathrm{~N}_{6} \mathrm{O}[\mathrm{M}+\mathrm{H}]+431.16 \mathrm{amu}$, found 431.1621amu.

6-amino-5-( I H-benzo[d]imidazol-2-yl)-I-hydroxy$2,3,4,4$ a-tetrahydrobenzo $[4,5]$ imidazo $[2,1-a]$ isoquinoline- I $2 \mathrm{~b}(\mathrm{I} \mathrm{H})$-carbonitrile (B2)

Into a round-bottomed flask was added glutaraldehyde 50\% solution in water $(1 \mathrm{mmol}), 345.8(2.2 \mathrm{mmol})$ of 2 , and trimethylamine $(1 \mathrm{mmol})$ in ethanol. This was left to stir at room temperature for an hour. The resulting white precipitate was filtered and washed with methanol to yield $337 \mathrm{mg}(85 \%)$ of product. 1H NMR $(400 \mathrm{MHz}$, DMSO-d $) \delta 12.5(\mathrm{~b}, \mathrm{OH}), 7.54(\mathrm{~s}, 4 \mathrm{H}), 7.2-7.1(\mathrm{~d}, \mathrm{t}, 4 \mathrm{H}), 5.52(\mathrm{~b}$, $\mathrm{NH}_{2}$ ), 4.09 (b, 2H), 1.8 (dd, 2H), 1.7 (d, 1H), 1.6-1.5 (d, dd,3H), ppm; $\delta{ }^{13} \mathrm{C}$ NMR $(100 \mathrm{MHz}$, DMSO-d $) \delta 151.56,121.58,117.96,72.43$, 58.36, 31.42, 19.61ppm. IR (KBr, $\left.v, \mathrm{~cm}^{-1}\right) 3431,3186,2254,1525$.

\section{5-amino-4-( I H-benzo[d]imidazol-2-yl)- | 2-hydroxy- 3 b, I 2-dihydro-I I bH-benzo[4,5]imidazo[ I, 2-a] thieno[3',2':3,4]cyclopenta[ I,2-c]pyridine- I I b- carbonitrile (B3)}

Into a round-bottomed flask was added $141 \mathrm{mg}$ of 2,3-thiophenedicarboxaldehyde (1 $\mathrm{mmol}), 345.8$ (2.2 $\mathrm{mmol})$ of 2 , and trimethylamine $(1 \mathrm{mmol})$ in ethanol. This was left to stir at room temperature for an hour. The resulting white precipitate was filtered and washed with methanol to yield $354 \mathrm{mg}(81 \%)$ of product. ${ }^{1} \mathrm{H}$ NMR (400MHz, DMSO-d $) \delta 8.33(\mathrm{~s}, 1 \mathrm{H}), 8.2(\mathrm{~s}, 1 \mathrm{H}), 8.08(\mathrm{~d}, 2 \mathrm{H})$, $7.99(\mathrm{~d}, 1 \mathrm{H}), 7.8(\mathrm{~d}, 2 \mathrm{H}), 7.7(\mathrm{~d}, 1 \mathrm{H}), 7.67(\mathrm{~d}, 1 \mathrm{H}), 7.57(\mathrm{t}, 2 \mathrm{H}), 7.45-$ $7.31(\mathrm{~m}, 6 \mathrm{H}), 7.22(\mathrm{~d}, 1 \mathrm{H}) \mathrm{ppm} ; \delta{ }^{13} \mathrm{C}$ NMR $(100 \mathrm{MHz}, \mathrm{DMSO}-\mathrm{d} 6)$ $\delta 146.35,145.98,142.52,142.47,142.18,138.64,136.54,134.48$, $134.11,133.5,133.02,130.46,129.97,126.56,123.89,123.75$, $123.52,119.52,117.88,117.77,111.44,111,20,104.63,102.99$, 73.15, 72.26ppm. IR (KBr, $\left.v, \mathrm{~cm}^{-1}\right) 3115,2226,1610,1584,1539$.

\section{Conclusion}

In conclusion, we have developed an efficient one-pot synthesis of benzo [4,5]imidazo[1,2-a]pyridine derivatives using a pseudo three-component reaction. This method we have demonstrated rapid construction of a indene fused benzo[4,5]imidazo[1,2-a]pyridine and hydroisoquinoline fused benzimidazole derivatives in good yields from simple dialdehydes and 2-(1H-benzo[d]imidazol-2-yl) acetonitrile in EtOH under normal conditions in the presence of trimethylamine as a base. Thus we have established a facile psuedo three component reaction protocol for accessing skeletally diverse benzo [4,5]imidazo[1,2-a]pyridine derivatives deverivatives with inherent provision for scaffold hopping.

\section{Acknowledgements}

Dr. G. Vasuki thank DST-SERB (SB/S1/OC-37/2014), Govt. of India, for financial support, and TSK thank CSIR for JRF and SRF (File No. 09/559(102)/2012-EMR- I). Authors also thank Central
Instrumentation Facility (CIF), Pondicherry University, for highresolution NMR and the Department of Chemistry for ESI-HRMS and single-crystal XRD.

\section{Conflict of interest}

Author declares that there is no conflict of interest.

\section{References}

1. Eisa HM, Bar-ghash AEM, Badr SM. Indian J Chem Sect B Org Chem Incl Med Chem. 2010;49:1515-1525.

2. Kotovskaya SK, Baskakova ZM, Charushin VN, et al. Synthesis and antiviral activity of fluorinated pyrido[1,2-a]benzimidazoles. Pharm Chem J. 2005;39(11):574-578.

3. Ndakala AJ, Gessner RK, Gitari PW, et al. Antimalarial Pyrido[1,2-a] benzimidazoles. J Med Chem. 2011;54(13):4581-4589.

4. Hranjec M, Kralj M, Piantanida I, et al. Novel Cyano- and Amidino-Substituted Derivatives of Styryl-2-Benzimidazoles and Benzimidazo[1,2-a]quinolines. Synthesis, Photochemical Synthesis, DNA Binding, and Antitumor Evaluation, Part 3. J Med Chem. 2007;50(23):5696-5711.

5. Dawood KM, Abdel-Wahabb BF. Synthetic routes to benzimidazolebased fused polyheterocycles. ARKIVOC. 2010;(i):333-389.

6. Deady LW, Rodemann T, Finalay GJ, et al. Synthesis and cytotoxic activity of carboxamide derivatives of benzimidazo[2,1-a]isoquinoline and pyrido[3',2':4,5]imidazo[2,1-a]isoquinoline. Anticancer Drug Des. 2001;15(5):339-346.

7. Xiao WL, Yang LM, Gong NB, et al. Rubriflordilactones A and B, Two Novel Bisnortriterpenoids from Schisandra rubriflora and Their Biological Activities. Org Lett. 2006;8(5):991-994.

8. Miri R, Javidnia K, Hemmateenejad B, et al. Synthesis, cytotoxicity, QSAR, and intercalation study of new diindenopyridine derivatives. Bioorg Med Chem. 2004;12(10):2529-2536.

9. Dömling A, Wang W, Wang K. Chemistry and Biology of Multicomponent Reactions. Chem Rev. 2012;112(6):3083-3135.

10. Kumaravel K, Vasuki G. Four-component catalyst-free reaction in water: Combinatorial library synthesis of novel 2-amino-4-(5-hydroxy-3-methyl1H-pyrazol-4-yl)-4H-chromene-3-carbonitrile derivatives. Green Chem. 2009;11(12):1945-1947.

11. Jayarajan R, Vasuki G. Building libraries of skeletally diverse scaffolds from novel heterocyclic active methylene compound through multicomponent reactions. Tet Lett. 2012;53(24):3044-3048.

12. Rajarathinam B, Kumaravel K, Vasuki G. Green chemistry oriented multi-component strategy to hybrid heterocycles. RSC Adv . 2016;6(77):73848-73852.

13. Feng X, Wang JJ, Xun Z, et al. Multicomponent Strategy to Indeno[2,1-c] pyridine and Hydroisoquinoline Derivatives through Cleavage of CarbonCarbon Bond. J Org Chem. 2015;80(2):1025-1033. 